\title{
From Where Does it Come? An Analysis of Currency Market Volatility in Sri Lanka
}

\author{
Sumila Tharanga Wanaguru*
}

\begin{abstract}
Exchange rate volatility is a key concern of policy makers. Existing literature has identified a large set of variables as the determinants of exchange rate volatility. However, it is argued that there are common shocks that underlie the co-movements of large time series used in such studies. Using the latent factor approach, which is naturally structured to identify such common shocks, this paper disentangles the unconditional volatility of six currencies expressed against the Sri Lankan rupee into common, numaraire and idiosyncratic factors to identify the sources of currency market volatility in Sri Lanka during the period from 2002-2012. Specifically, this paper attempts to investigate whether the volatility of currency market in Sri Lanka stems from domestic currency market specific sources or external sources. Care is taken to distinguish the effects on intervention and non-intervention days. Empirical results suggest that currency market volatility in Sri Lanka is primarily externally sourced. Prior to the financial crisis, policy makers are found to have been primarily focused on mitigation of the volatility coming from the US currency market, whereas during the crisis this was expanded to include volatility emanating from European currency markets in what may be characterised as an attempt to minimise Sri Lanka's exposure to global events at the time. However, the policy change introduced in early 2012 by limiting the Central Bank intervention in the foreign exchange market can be identified as an effective policy measure which has reduced exchange rate volatility arises in the domestic currency market.
\end{abstract}

Keywords: Exchange Rate Volatility, Latent Factor Model, Sri Lanka

JEL Classification: C38, C51, F31, G15

* This research paper fulfills the requirement of the Macroeconomic Modeling Unit established recently under the Economic Research Department. The author wishes to thank Dr. D. S. Wijesinghe and Dr. M. Z. M. Aazim for their valuable comments. Corresponding e-mail: sumila@cbsl.lk 


\section{Introduction}

Exchange rate volatility is a key concern of policy makers. Excessive volatility in the foreign exchange market can impair the smooth functioning of the financial system and economic performances as the exchange rate has a strong influence on foreign trade, capital flows and economic development. Therefore, policy makers tend to adopt various policies to curb excess volatility in exchange rate movements.

Understanding the causes of exchange rate volatility provides valuable insight for policy makers to design appropriate measures or intervention strategies in mitigating a country's vulnerability to risk in periods of uncertainty. Moreover, identifying the sources of exchange rate volatility is important, as maintaining a competitive and stable exchange rate is necessary for promoting private investment, domestic and foreign, needed to meet the growth and development targets in the country. Although a voluminous of scholarly articles can be found on exchange rate volatility, there is no consensus in the literature on the factors which affect exchange rate volatility, either by individual country or across panels (Abdalla, 2012; Canales-Kriljenko and Habermeier, 2004). Existing studies identify a number of factors which contribute to the volatility of exchange rate. These factors include, but are not limited to, level of output, openness of an economy, domestic and foreign money supplies, exchange rate regime, policy intervention, inflation, interest rates, central bank independence, income and external shocks (Stančík, 2009).

A careful investigation of the factors influencing exchange rate volatility reveals that the dynamic behaviour of exchange rates broadly stems from two factors; $(i)$ factors unique to the domestic currency market, and (ii) factors which spill-over from currency market interdependencies. The latter is viewed as external factors. Introducing the so-called "meteor shower" hypothesis, Engle et al. (1990) have suggested that volatility spills-over, rather than remaining in one market. Although the majority of the existing studies focuses on investigating the determinants of exchange rate volatility, the individual characteristics of exchange rate returns and the degree of the impact of each of these variables, only a handful of studies attempts to disentangle exchange rate volatility to identify the contribution of domestic currency market related factors and external factors. Diebold and Nerlove (1989), Mahieu and Schotman (1994), Dungey (1999) and Dungey and Martin (2004) are exceptions. This paper aims to fill that gap in literature.

The objective of this paper is to decompose the volatility of bilateral exchange rates of a selection of Sri Lanka's trading partner currencies, expressed against the Sri Lankan rupee, into factors unique to domestic currency market and external factors to investigate the sources of domestic currency market volatility in Sri Lanka. ${ }^{1}$ The motivation of

1 The term "domestic factors" is used in this paper to represent factors uniquely attributed to the domestic currency market and the term "external" is used to represent factors which do not uniquely stem from the domestic currency market. 
this paper is the fact that the effective mitigation of exchange rate volatility depends on understanding its sources. Dungey (1999) put forward this idea by suggesting that national monetary authorities can only play a limited role in reducing exchange rate volatility, while maintaining a floating exchange rate regime, if such volatility is primarily stemmed from external sources. Conversely, economic costs associated with exchange rate volatility could potentially be mitigated by appropriate policy measures, if the volatility of exchange rate is primarily originated from domestic currency market related sources as domestic sources of such volatility are more likely to be amenable to policy initiatives of the domestic monetary authority.

The empirical investigation of this paper is based on the latent factor structure of exchange rate movements proposed by Diebold and Nerlove (1989) and Mahieu and Schotman (1994). ${ }^{2}$ In economics, factors are defined as common shocks that underlie the co-movements of the large number of economic time series (Bai and $\mathrm{Ng}, 2006, \mathrm{p} .1$ ). As in the latent factor model literature, these factors are not directly observable (Dungey and Martin, 2004; Heston and Rouwenhorst, 1995). In fact, the identfication of key variables for existing studies on exchange rate volatility is somewhat ad hoc, mainly because it is impossible to incorporate all the variables that may affect dynamic features of exchange rate movements. To overcome this problem some studies such as Bai and $\mathrm{Ng}$ (2006); Verdelhan (2012) and Engel et al. (2012) have tried to identify whether there is commonality in the empirical characteristics of exchange rate returns. This provides a justification for the use of a small set of latent factors as in Diebold and Nerlove (1989); Engle et al. (1990); Kose et al. (2003); Mahieu and Schotman (1994); Ng et al. (1992) and Dungey et al. (2005) to specify a parsimonious multivariate model of time varying volatility. That is, latent factor analysis can be used to summarize a rich data set with a simpler underlying structure.

The way that the latent factor model can be specified and estimated to decompose exchange rate volatility is explained in detail in Dungey (1999), the closest to this paper. However, the current paper is different to earlier work in the area of interest in two ways. First, the current paper mainly focusses on disentangling exchange rate volatility of a set of Sri Lanka's trading partner currencies into domestic currency market related factors and external factors, which has not been studied previously. Second, the current paper takes foreign exchange intervention by the Central Bank of Sri Lanka into account, by separately modelling the dynamic behaviour of currencies involved with the Sri Lankan rupee for days on which the Central Bank intervenes in the domestic foreign exchange

2 The other method that is used widely to decompose exchange rate volatility is the Vector Auto-Regression (VAR) Analysis, and the use of VARs to model dynamics of exchange rate movements is well published (Berument and Pasaogullari, 2003; Ito and Sato, 2008; Karras et al., 2005; Odusola and Akinlo, 2001). 
market and for days on which there is no intervention. Previous studies such as Diebold and Nerlove (1989); Engle et al. (1990) and Dungey et al. (2005) have not considered this phenomenon when decomposing exchange rate volatility. ${ }^{3}$ However, this study does not formally model currency market intervention in Sri Lanka. ${ }^{4}$

The analytical framework consists of modelling each exchange rate return series as a linear combination of three factors, as in Engle et al. (1990); Heston and Rouwenhorst (1995) and Dungey (1999): a common factor that impacts upon all exchange rate returns, a numeraire factor that is uniquely associated with the numaraire currency, and an idiosyncratic factor that captures the variations in a specific currency market. The currencies examined in this paper are euro (EUR), the British pound (GBP), the Japanese yen (JPY), the US dollar (USD), the Indian rupee (INR) and the Pakistan rupee (PKR), all against the Sri Lankan rupee (LKR). The latent factor model of panel of exchange rate returns is estimated through Generalised Method of Moments (GMM) for the period prior to the current financial crisis, January 2002 - June 2007, and for the crisis period, July 2007 - August 2012. The empirical investigation is further extended by decomposing exchange rate volatility during the period from February-August 2012 to identify the impact of the changes introduced to the exchange rate policy in Sri Lanka in February 2012, by limiting the Central Bank intervention in the domestic foreign exchange market to allow for more exibility in determining the exchange rate.

Empirical results reveal that exchange rate volatility mainly stems from the factors external to the domestic currency market in Sri Lanka. Except for the decomposition of the US dollar/Sri Lankan rupee exchange rate volatility on non-intervention days in the pre-crisis period, at least 70 per cent of total volatility of the currency market is explained by external factors - that is by common and idiosyncratic factors. Exhibiting that the domestic monetary authority can do little in reducing volatility when the contribution of external factors is large, domestic currency market volatility is larger when the Central Bank intervenes either by buying or selling US dollars. Overall, the volatility decomposition of intervention day models in both periods suggests that policy response of the Central Bank of Sri Lanka mainly aims volatility spills-over from external factors rather than factors which are unique to the domestic currency market. During the pre-crisis period, this response was rested on US currency market specific factors, but the response in the crisis period was mainly aimed at US dollar and euro specific factors. The latter can be viewed as a response to the recent financial crisis and the ensuing debt problems in the US and Europe.

3 Not considering currency market intervention by monetary authorities in existing studies may be due to lack of availability of data or intervention is not very frequent in the countries studied.

4 See Fry-McKibbin and Wanaguru (2013) for an application of the latent factor specification in modelling currency market intervention. 
Re-running the model for the period from February 2012 - August 2012, this paper finds that the contribution of the domestic currency market related (numaraire) factors is considerably larger during this period when the Central Bank does not intervene. The contribution of the numaraire factor, however, has decreased significantly as the Central Bank intervenes in the foreign exchange market. This, not only suggests that the Central Bank has been able to mitigate the impact of domestic currency market related factors, but also indicates that the current exchange rate policy stance is appropriate in the context of reducing the contribution domestic factors made to the total volatility of the Sri Lankan rupee. However, the adequacy of data for this sub-period remains a concern.

The rest of the paper is organized as follows. Section 2 develops the latent factor model of exchange rate returns. Section 3 presents GMM methodology used in the analysis. Section 4 discusses the statistical properties of data, while Section 5 presents empirical results. Section 6 concludes.

\section{The Model}

This section specifies a latent factor model of exchange rate returns, distinguishing between non-intervention days and intervention days. Latent factor analysis, which originated in psychometrics, is a statistical method applied to explain the variability among observed and correlated variables in terms of a fewer number of unobserved variables. These unobserved variables are called factors. In other words, the latent factor model identifies the common shocks that underlie the co-movements of large time series, thus allowing the variations in a set of observed variables to reflect the variations in fewer unobserved variables. Using latent variables helps in reducing the dimensionality of data by aggregating a large number of variables in a model to represent an underlying concept and making it easier to understand data. Therefore, applying the latent factor methodology to investigate the factor structure of the dynamic nature of exchange rate volatility provides a parsimonious and convenient way of representing data, whilst implicitly taking into account all the disturbances affecting the set of exchange rate returns included in the model. All the factors are assumed to be independent latent stochastic processes with zero means and unit variances. This facilitates the decomposition of unconditional volatility of exchange rate returns according to the contribution that each of the factors makes to overall volatility.

The non-intervention day model is specified assuming that the volatility of exchange rate returns can be captured through a "common" factor, which affects all foreign exchange markets simultaneously; a "numaraire" factor which captures variations unique to the 
numaraire currency, here the Sri Lankan rupee; and "idiosyncratic" factors which are specific to each foreign exchange market in a particular country. 5

The intervention day model is also built with the same assumptions, but the effect of each factor on each exchange rate return, as given by the factor loadings, is allowed to change through the formal modelling of structural breaks as in Fry-McKibbin and Wanaguru (2013). This treatment allows capturing changes in external and domestic dependence structures among the exchange rate returns such as possible high volatility which may be prevalent on the days that the Central Bank of Sri Lanka chooses to intervene (Fry-McKibbin and Wanaguru, 2013).

Denoting the percentage change in the exchange rate between currency $i$, and the numeraire currency, $x$, on non-intervention days $(N I)$ at time $t$ as $R_{i, x, t}^{N I}$, the model of exchange rate volatility can be presented as a linear combination of three factors given by:

$$
R_{i, x, t}^{N I}=\lambda_{i, x}^{N I} W_{t}+\eta_{x}^{N I} N_{t}+v_{i, x}^{N I} C_{t}
$$

where, $i=E U R, G B P, I N R, J P Y, P K R$ and $U S D$.

In matrix form, the model of exchange rate returns can be expressed as:

$$
\left[\begin{array}{c}
R_{E U R, x, t}^{N I} \\
R_{G B P, x, t}^{N I} \\
R_{I N R, x, t}^{N I} \\
R_{J P Y, x, t}^{N I} \\
R_{P K R, x, t}^{N I} \\
R_{U S D, x, t}^{N I}
\end{array}\right]=\left[\begin{array}{cccccccc}
\lambda_{1}^{N I} & \eta_{x}^{N I} & v_{1, x}^{N I} & 0 & 0 & 0 & 0 & 0 \\
\lambda_{2}^{N I} & \eta_{x}^{N I} & 0 & v_{2, x}^{N I} & 0 & 0 & 0 & 0 \\
\lambda_{3}^{N I} & \eta_{x}^{N I} & 0 & 0 & v_{3, x}^{N I} & 0 & 0 & 0 \\
\lambda_{4}^{N I} & \eta_{x}^{N I} & 0 & 0 & 0 & v_{4, x}^{N I} & 0 & 0 \\
\lambda_{5}^{N I} & \eta_{x}^{N I} & 0 & 0 & 0 & 0 & v_{5, x}^{N I} & 0 \\
\lambda_{6}^{N I} & \eta_{x}^{N I} & 0 & 0 & 0 & 0 & 0 & v_{6, x}^{N I}
\end{array}\right]\left[\begin{array}{c}
W_{t} \\
N_{t} \\
C_{1, t} \\
C_{2, t} \\
C_{3, t} \\
C_{4, t} \\
C_{5, t} \\
C_{6, t}
\end{array}\right]
$$

5 Several alternative model structures with other possible factors such as regional and market factors were considered in the preliminary stage of the empirical investigation. However, computationally the models with these specifications did not work in this study. 
The term $W_{t}$ represents the common factor that affects all exchange rate returns, but with different parameter loadings for each currency return. The loading parameter of the common factor is denoted as $\lambda_{i, x}^{N I}$. The term $N_{t}$ captures shocks specific to the numaraire currency. The impact on each currency is fixed and given by $\eta_{x}^{N I}$. Imposing no arbitrage condition and presenting the exchange rates relative to a common numeraire, here the Sri Lankan rupee, leads to the loading parameter $\eta_{x}^{N I}$ to be fixed, reducing the parameterisations (Dungey, 1999). The set of idiosyncratic factors which capture country specific effects in currency market is given by $C_{t}$, with factor loading $v_{i, x}^{N I}$. The intervention day model is slightly different to the non-intervention day model as it is assumed that the Central Bank intervenes in the foreign exchange market as a consequence of higher excess volatility in the foreign exchange market. As in Fry-McKibbin and Wanaguru (2013), this phenomenon is captured through introducing structural breaks in modelling the factor structure of exchange rate volatility. Therefore, the dynamics of exchange rate returns for intervention days $(I)$ takes the form:

$$
R_{i, x, t}^{I}=\left(\lambda_{i, x}^{N I}+\lambda^{I}\right)_{i, x} W_{t}+\left(\eta_{x}^{N I}+\eta_{x}^{I}\right) N_{t}+\left(\nu_{i, x}^{N I}+\nu_{i, x}^{I}\right) C_{t},
$$

In matrix form, the model of exchange rate returns can be expressed as:

$$
\begin{aligned}
& {\left[\begin{array}{l}
R_{E U R, x, t}^{I} \\
R_{G B P, x, t}^{I} \\
R_{I N R, x, t}^{I} \\
R_{J P Y, x, t}^{I} \\
R_{P K R, x, t}^{I} \\
R_{U S D, x, t}^{I}
\end{array}\right]=\left[\begin{array}{ll}
\left(\lambda_{1}^{N I}+\lambda_{1}^{I}\right) & \left(\eta_{x}^{N I}+\eta_{x}^{I}\right) \\
\left(\lambda_{2}^{N I}+\lambda_{2}^{I}\right) & \left(\eta_{x}^{N I}+\eta_{x}^{I}\right) \\
\left(\lambda_{3}^{N I}+\lambda_{3}^{I}\right) & \left(\eta_{x}^{N I}+\eta_{x}^{I}\right) \\
\left(\lambda_{4}^{N I}+\lambda_{4}^{I}\right) & \left(\eta_{x}^{N I}+\eta_{x}^{I}\right) \\
\left(\lambda_{5}^{N I}+\lambda_{5}^{I}\right) & \left(\eta_{x}^{N I}+\eta_{x}^{I}\right) \\
\left(\lambda_{6}^{N I}+\lambda_{6}^{I}\right) & \left(\eta_{x}^{N I}+\eta_{x}^{I}\right)
\end{array}\right]\left[\begin{array}{c}
W_{t} \\
N_{t}
\end{array}\right]+} \\
& {\left[\begin{array}{cccccc}
\left(\nu_{1, x}^{N I}+\nu_{1, x}^{I}\right) & 0 & 0 & 0 & 0 & 0 \\
0 & \left(\nu_{2, x}^{N I}+\nu_{2, x}^{I}\right) & 0 & 0 & 0 & 0 \\
0 & 0 & \left(\nu_{3, x}^{N I}+\nu_{3, x}^{I}\right) & 0 & 0 & 0 \\
0 & 0 & 0 & \left(\nu_{4, x}^{N I}+\nu_{4, x}^{I}\right) & 0 & 0 \\
0 & 0 & 0 & 0 & \left(\nu_{5, x}^{N I}+\nu_{5, x}^{I}\right) & 0 \\
0 & 0 & 0 & 0 & 0 & \left(\nu_{6, x}^{N I}+\nu_{6, x}^{I}\right)
\end{array}\right]\left[\begin{array}{c}
C_{1, t} \\
C_{2, t} \\
C_{3, t} \\
C_{4, t} \\
C_{5, t} \\
C_{6, t}
\end{array}\right]}
\end{aligned}
$$

The zero mean assumption constraints any intercept term in Equations (1) and (3). The unit variance assumption makes all covariances between the latent factors interpretable as correlations. Therefore, using Equation (1), the unconditional volatility of currency returns on non-intervention days can be expressed as the variance:

$$
V A R\left(R_{i, x, t}^{N I}\right)=E\left[\left(R_{i, x, t}^{N I}\right)^{2}\right]=\left(\lambda_{i, x}^{N I}\right)^{2}+\left(\eta_{x}^{N I}\right)^{2}+\left(\nu_{x}^{N I}\right)^{2}
$$


The unconditional volatility of currency returns on intervention days can be given by:

$$
V A R\left(R_{i, x, t}^{I}\right)=E\left[\left(R_{i, x, t}^{I}\right)^{2}\right]=\left(\lambda_{i, x}^{N I}+\lambda_{i, x}^{I}\right)^{2}+\left(\eta_{x}^{N I}+\eta_{x}^{I}\right)^{2}+\left(\nu_{i, x}^{N I}+\nu_{i, x}^{I}\right)^{2}
$$

A useful description of the unconditional volatility of exchange rate returns given in Equations (5) and (6) is these equations allow to decompose the effects of shocks into common, numaraire and idiosyncratic components. The total decomposition of exchange rate volatility on intervention days can be re-expressed using Equation (6) as a proportion of the contribution of each factor as follows:

$$
\begin{aligned}
& \text { Contribution of the common factor }=\frac{\left(\lambda_{i, x}^{N I}+\lambda_{i, x}^{I}\right)^{2}}{\left(\lambda_{i, x}^{N I}+\lambda_{i, x}^{I}\right)^{2}+\left(\eta_{x}^{N I}+\eta_{x}^{I}\right)^{2}+\left(\nu_{i, x}^{N I}+\nu_{i, x}^{I}\right)^{2}} \\
& \text { Contribution of the numaraire factor }=\frac{\left(\eta_{i x}^{N I}+\eta_{x}^{I}\right)^{2}}{\left(\lambda_{i, x}^{N I}+\lambda_{i, x}^{I}\right)^{2}+\left(\eta_{x}^{V}+\eta_{x}^{I}\right)^{2}+\left(\nu_{i, x}^{N I}+\nu_{i, x}^{I}\right)^{2}} \\
& \text { Contribution of the idiocyncratic factor }=\frac{\left(\nu_{i, x}^{N I}+\nu_{i, x}^{I}\right)^{2}}{\left(\lambda_{i, x}^{N I}+\lambda_{i, x}^{I}\right)^{2}+\left(\eta_{x}^{N I}+\eta_{x}^{I}\right)^{2}+\left(\nu_{i, x}^{N I}+\nu_{i, x}^{I}\right)^{2}}
\end{aligned}
$$

Similarly, the proportionate contribution of each factor on non-intervention days can be presented using Equation (3), but suppressing the structural break terms. This presentation allows the unconditional volatility of the exchange rate returns of each currency expressed against the Sri Lankan rupee to be decomposed into domestic and external factors: the first and the third terms of Equations (5) and (6), the $\lambda$ and $v$ terms, to represent the contributions of external factors, and the second term, $\eta$, to represent the contribution of the factors unique to domestic currency market.

\section{Methodology}

The latent factor model of exchange rate volatility is estimated through the Generalized Method of Moments (GMM). GMM provides a unified framework for inference in econometrics to obtain consistent and asymptotically normally distributed estimators of the parameters. Existing literature has identified GMM as a method that provides a solution to the problems of simultaneity bias, omitted variable bias and reverse causality. Additionally, GMM estimators are robust to failures of 'auxiliary distributional' assumptions that are not needed to identify key parameters (Wooldridge, 2001:87). Another important feature of this methodology is that it is generally better under Heteroskedasticity, and allows the parameters to be over-identified (Cragg, 1983; Wooldridge, 2001). 
The estimation procedure is based on computing the unknown parameters by equating the theoretical moments of the model to the empirical moments of the data in both the non-intervention day model and the intervention day model. The non-intervention day model is jointly estimated with the intervention day model. Therefore, the entire model consists of 42 theoretical moments of which $[6 *(6+1)] / 2=21$ comes from the non-intervention day model while the remainder comes from the intervention day model. There are 26 unknown parameters to estimate.

The objective function of the GMM estimator:

$$
S(\theta)=X_{N I}^{\prime}(\theta) V_{N I}(\theta)^{-1} X_{N I}(\theta)+X_{I}^{\prime}(\theta) V_{I}(\theta)^{-1} X_{I}(\theta)
$$

is minimized accounting for both non-intervention days and intervention days. The term $\theta$ in Equation (10) is the parameter vector. The weighting matrices, $V_{(.)}(\theta)$, are corrected for possible Heteroskedasticity in the moment conditions (Hamilton, 1994; Newey and West, 1987). An optimal weighting matrix can be obtained for a GMM analysis subject to the set of population moment conditions (Wooldridge, 2001). The GMM estimators are obtained by iterating both the parameters and weighting matrices until the convergence of the empirical and theoretical moments. $X_{(.)}(\theta)$ are the vectors containing the differences between the empirical moments and the theoretical moments, and are given by:

$$
\begin{gathered}
X_{N I}(\theta)=\operatorname{vech}\left(\Omega_{N I}(\theta)\right)-\operatorname{vech}\left(\Psi_{N I}(\theta) \Psi_{N I}^{\prime}(\theta)\right) \\
X_{I}(\theta)=\operatorname{vech}\left(\Omega_{I}(\theta)\right)-\operatorname{vech}\left(\Psi_{I}(\theta) \Psi_{I}^{\prime}(\theta)\right)
\end{gathered}
$$

where $\Omega_{(.)}(\theta)$ and $\Psi_{(.)}(\theta) \Psi_{(.)}^{\prime}(\theta)$ are the empirical and theoretical variance-covariance matrices, respectively, which are defined as:

and

$$
\left.\left.\Omega_{\tau}(\theta)=\frac{1}{T_{\tau}} \sum_{t \in T_{\tau}} \varepsilon_{t}(\theta)\right) \varepsilon_{t}^{\prime}(\theta)\right) \text { where } \tau=N I, I
$$

$$
E\left[\varepsilon_{t}(\theta) \varepsilon_{t}^{\prime}(\theta)\right]_{t \epsilon T_{\tau}}=\Psi_{(\tau)}(\theta) \Psi_{(\tau)}^{\prime}(\theta) \text { where } \tau=N I, I
$$


Finally, it is desired to check for the adequacy of the model using an over-identifying restrictions test as the number of theoretical moment conditions is greater than the number of empirical moment conditions in the model. Usually, the over-identifying restrictions are tested using Hansen's $J$-static to test the null hypothesis that the model is correctly specified. The $J$ test is given by:

$$
J(\theta)=\operatorname{TS}(\theta)
$$

where $T$ is the total number of observations in the full model given by $T=T_{N I}+T_{I}$. Here, $J(\theta)$ converges to the $X_{p-q}^{2}$ distribution asymptotically, with $p$ number of moment conditions and $q$ number of parameters. If over-identifying restrictions are rejected, it suggests that the variables included in the model fail to satisfy the orthogonality condition.

\section{Data Description}

The data consists of high frequency daily observations of bilateral exchange rates of the euro, the British pound, the Japanese yen, the Indian rupee, the Pakistan rupee and the US dollar, expressed against the Sri Lankan rupee, over the period from January 01, 2002 to August 30, 2012. All the data are obtained from the Central Bank of Sri Lanka. The selection of currencies depends on Sri Lanka's major trading partners, who follow floating exchange rate regimes. Additionally, the euro, the British pound, the Japanese yen and the US dollar represent advanced foreign exchange markets, whilst the Indian rupee and the Pakistan rupee represent emerging markets. An increase in the value of the exchange rate indicates an appreciation of the Sri Lankan rupee against other currencies.

Daily exchange rates of the selection of currency pairs are shown in Figure 1, and the summary statistics are presented in Table 1 . The continuously compounded exchange rate returns $\left[R_{i, t}=\ln \left(e_{i, t}\right)-\ln \left(e_{i, t-1}\right)\right]$ are depicted in Figure 2. The outliers in the euro on March 1 and 2, 2005, and in the Pakistan rupee on July 31 and August 01, 2003 as depicted in Figure 2 are removed using dummy variables in the empirical analysis. All the return series are standardized to have zero mean and unit variance to facilitate convergence in the estimating procedure. 
EUR

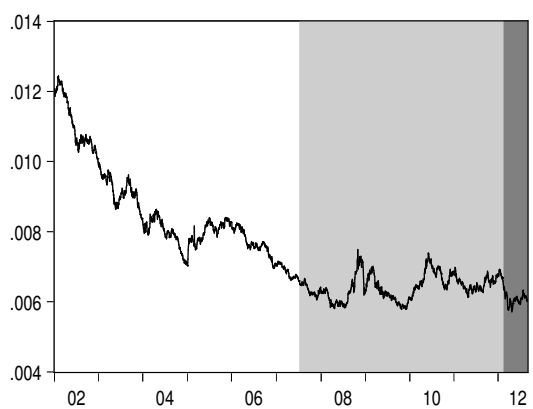

INR

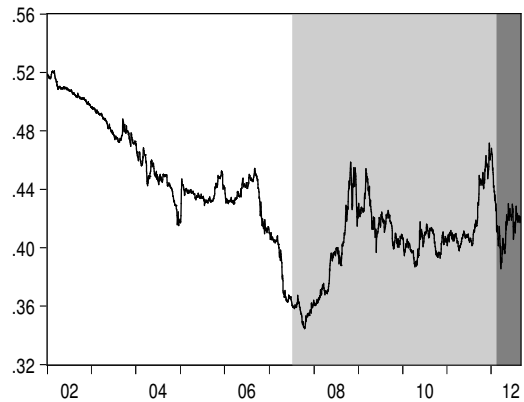

PKR

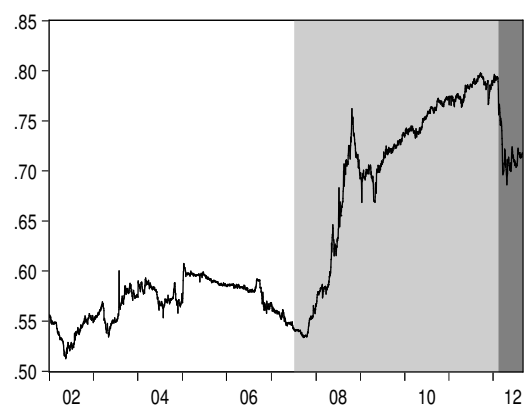

GBP

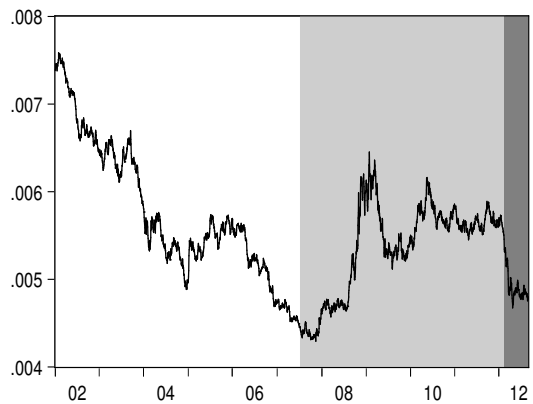

JPY

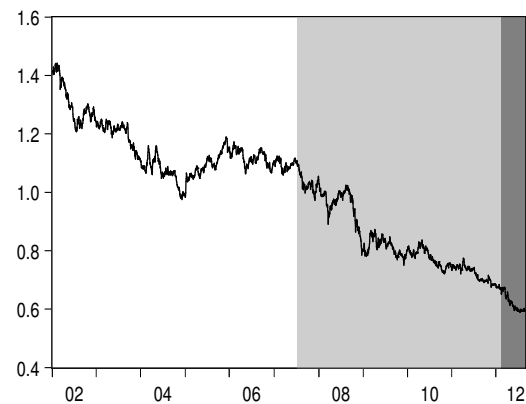

USD

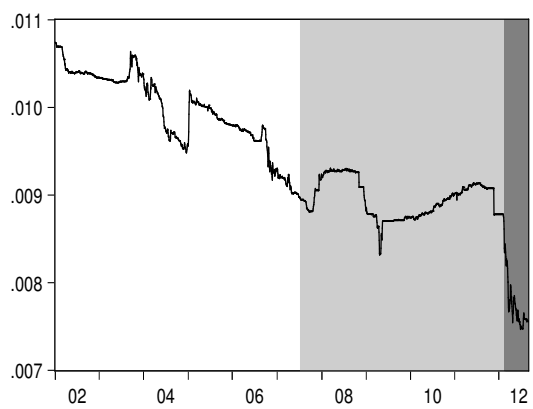

\section{Figure 1:}

Daily Exchange Rates of the euro, the British pound, the Indian rupee, the Japanese yen, the Pakistan rupee and the US dollar against the Sri Lankan rupee, January 2002 - August 2012. An increase in the value of the exchange rate indicates an appreciation of the Sri Lankan rupee. The shaded area indicates the period of global volatility from July 02, 2007 - August 30, 2012, while the dark shaded area represents the period from February 2012 - August 2012 - the period after changing the exchange rate policy stance.

Source : Central Bank of Sri Lanka 
DLNEUR

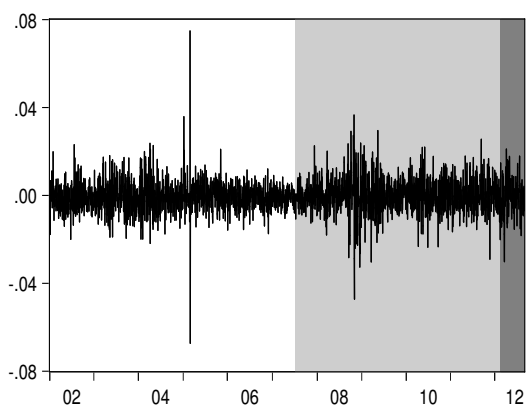

DLNINR

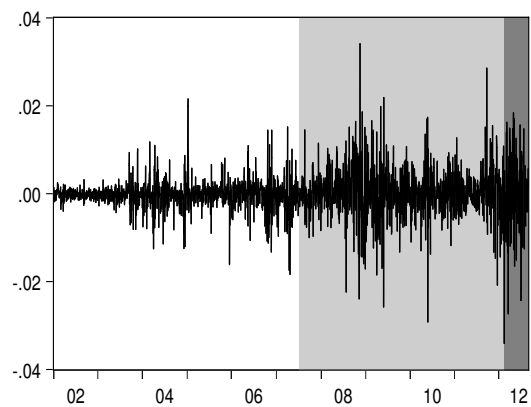

DLNPKR

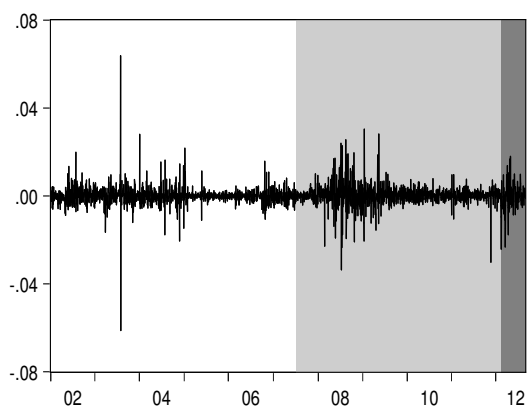

DLNGBP

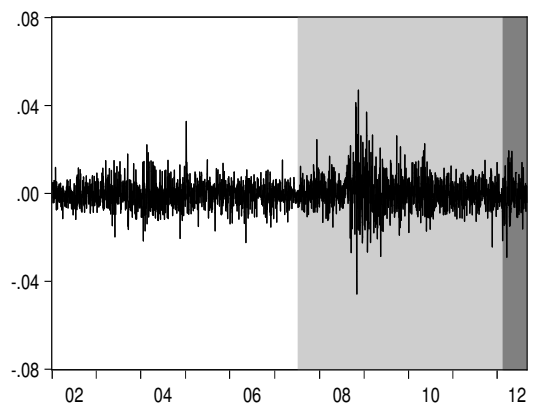

DLNJPY

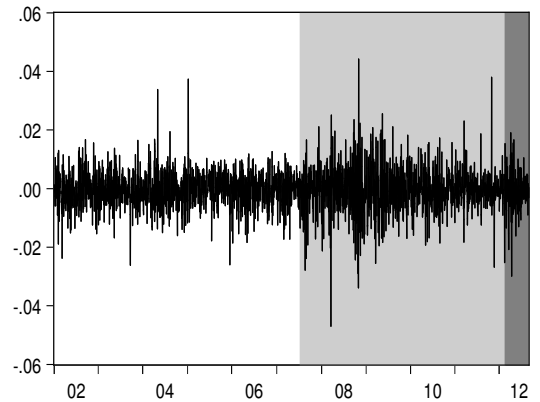

DLNUSD

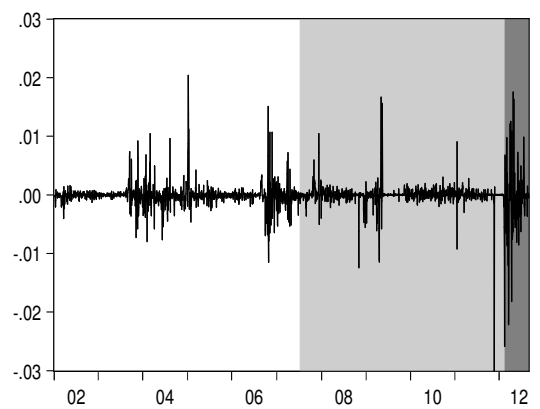

\section{Figure 2:}

Daily Exchange Rate Returns of the euro, the UK pound, the Indian rupee, the Japanese yen and the US dollar against the Sri Lankan rupee, January 2002 - August 2012. An increase in the value of the exchange rate indicates an appreciation of the Sri Lankan rupee. The shaded area indicates the period of global volatility from July 02, 2007 - August 30, 2012, while the dark shaded area represents the period from February 2012 - August 2012 - the period after changing the exchange rate policy stance.

Source : Central Bank of Sri Lanka 


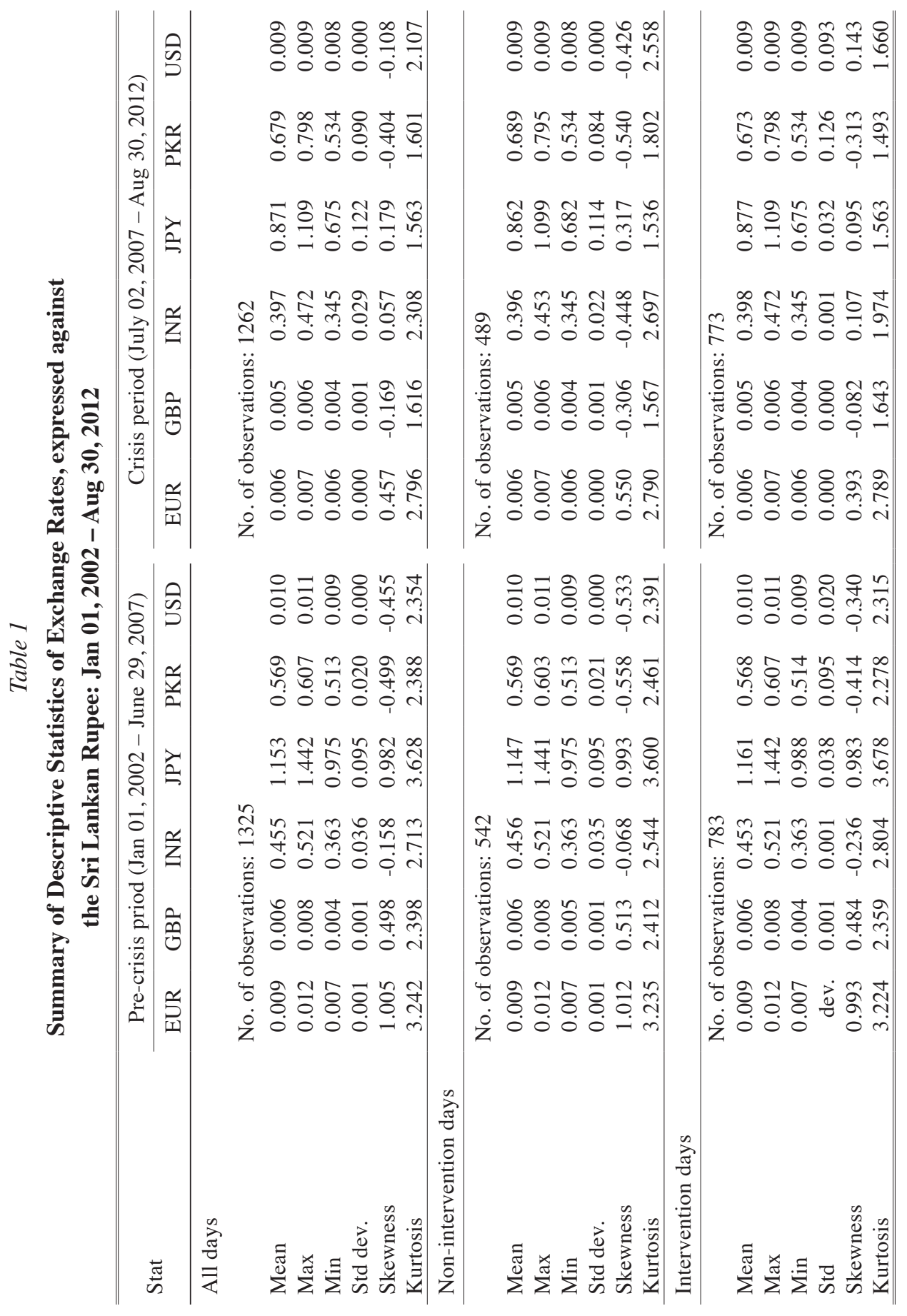


Some of the existing literature explicitly model heteroskedasticity through a generalized autoregressive conditional heteroskedasticity, in order to capture the volatility clustering phenomenon that can be observed in high frequency financial time series. This paper, however, does not focus on specifying GARCH conditional volatilities on the factors structured in Section 2 as it leads to an over parameterised model. Instead, possible heteroskedasticity is controlled in accomplishing the model through GMM.

\section{Results}

This section disentangles the exchange rate volatility as per the factor model Equations (5) and (6) discussed in Section 2. Section 5.1 presents the decomposition of exchange rate volatility during the pre-crisis period, whilst Section 5.2 presents the same for the crisis period. In both cases, the results are reported distinguishing non-intervention days and intervention days. Also, it is worth mentioning that the Central Bank of Sri Lanka intervenes by absorbing and supplying US dollars, expecting to impact upon other foreign currency rates through cross currency exchange rate movements.

\subsection{Pre-crisis period}

The decomposition of exchange rate volatility of the six exchange rates, expressed against the Sri Lankan rupee, is presented in Table 2. Disentangling exchange rate volatility into common, numaraire and idiosyncratic factors allows policy makers to understand the influence of domestic and external factors on overall exchange rate volatility as discussed in Section 2. The $J$-test is satisfied with a value of 34.22 and a $p$-value of 0.705. The number of degrees of freedom is 16 .

As it can be seen in Table 2, volatility in exchange rates is mainly driven by the external factors (common and idiosyncratic factors), rather than the factors which arise in the domestic foreign exchange market. The only exception is the US dollar/ Sri Lankan rupee exchange rate during non-intervention days, where 51 per cent of the total volatility is attributed to the numaraire factor. The conclusion that the volatility is primarily externally sourced can be seen contrary to the general perception of the rupee exchange rate movements in Sri Lanka as it is believed that the exchange rate responds primarily to domestic market conditions such as availability and demand for foreign exchange. However, in this study, word "external" refers to factors which are not uniquely associated with the domestic foreign exchange market, hence it does not necessarily refer to international factors. Nevertheless this emphasizes the need for further investigations in this field of study as even this general perception is not validated through any quantitative analysis thus far. The large contribution of the numaraire factor to the 
volatility of the US dollar/Sri Lankan rupee exchange rate during the pre-crisis period under no intervention reflects the fact that the US dollar/Sri Lankan rupee exchange rate is independently determined while the exchange rate against other currencies are determined by applying the US dollar/Sri Lankan rupee exchange rate to their cross rates against the US dollar, as most of the transactions in the foreign exchange market are in US dollars.

Table 2

Volatility Decomposition during the Pre-crisis Period, in per cent

\begin{tabular}{crrc}
\hline \hline & Common & Numaraire & Idiosyncratic \\
\hline Non-intervention days & & & \\
\hline EURO & 61.618 & 2.317 & 36.065 \\
GBP & 71.129 & 2.465 & 26.406 \\
INR & 1.823 & 3.682 & 94.495 \\
JPY & 34.511 & 2.542 & 62.947 \\
PKR & 0.024 & 5.228 & 94.747 \\
USD & 9.182 & 51.034 & 39.784 \\
\hline Intervention days & & & \\
\hline EURO & 37.586 & 28.616 & 33.798 \\
GBP & 38.892 & 28.042 & 33.066 \\
INR & 2.497 & 30.107 & 67.396 \\
JPY & 14.280 & 28.030 & 57.689 \\
PKR & 2.929 & 17.569 & 79.502 \\
USD & 3.262 & 35.703 & 61.035 \\
\hline \hline
\end{tabular}

Note: Volatility decomposition is based on the contribution to the total volatility. Exchange rates are expressed against 1 unit of the Sri Lankan rupee.

It is also clear that more than 60 per cent of volatility of the euro/Sri Lankan rupee and British pound/Sri Lankan rupee exchange rate returns is due to the common factor in the non-intervention days, whilst more than 94 percent of Indian rupee/Sri Lankan rupee and Pakistan rupee/Sri Lankan rupee volatility stems from the idiosyncratic factors. With the exception of the Japanese yen, the common factor plays a large role in volatility of the currencies that represent advanced countries on non-intervention days. In the case of emerging market currencies, a considerable component of exchange rate volatility is attributed to the factors unique to their own foreign exchange markets. The contribution of the common factor to the volatility of these currencies is considerably small. However, capturing the contribution of domestic currency market specific factors which are transmitted through the US dollar/Sri Lankan rupee exchange rate remains an issue here. 
The volatility decomposition of the intervention days provide some insight about the foreign exchange market in Sri Lanka. The most interesting observation here is the volatility of the US dollar/Sri Lankan rupee exchange rate return, where 61 percent of overall volatility comes from the US dollar market (idiosyncratic US dollar factor). Noting that the Central Bank of Sri Lanka intervenes only by absorbing or supplying US dollars, the volatility decomposition of the US dollar/Sri Lankan rupee in non-intervention days and intervention days suggests that the Central Bank intervenes in the foreign exchange market when the US foreign exchange market is highly volatile. This result, in fact, is in line with Fry-McKibbin and Wanaguru (2013), in which they have expressed the exchange rate as the amount of Sri Lankan rupees per unit of the US dollar. ${ }^{6}$

Although the contribution of the factors uniquely attributed to the domestic foreign exchange market (numaraire factor) to the overall volatility of the US dollar/Sri Lankan rupee exchange rate has decreased on intervention days compared to that of the non-intervention days, the contribution of the numaraire factor to all other currencies considered in the model is larger even if the Central Bank intervenes in the market. The relatively large contribution of domestic currency market specific factors to other currencies may be attributed to the higher variance of the US dollar/Sri Lankan rupee exchange rate. The variance of the US dollar/Sri Lankan rupee exchange rate is higher on intervention days compared to that of the non-intervention days and this variance seems high enough to make a relatively higher contribution to the variance of other bilateral exchange rates.

\subsection{Crisis period}

The factor model of exchange rate returns is re-run in this section for the crisis period and the results are presented in Table 3. As in the pre-crisis period model, this model also satisfies the $J$-test with a value of 26.74 and a $p$-value of 0.144 with 16 degrees of freedom.

The results indicate that the volatility of all exchange rate returns, including the US dollar/Sri Lankan rupee rate, in both the non-intervention and intervention regimes stems from external sources. The contribution of the factors attributed to the domestic currency market is 20 per cent in the euro/Sri Lankan rupee and the US dollar/Sri Lankan rupee exchange rates, but less than 4 per cent in all other cases.

6 Although one can interpret relatively higher contribution of the US dollar market as simply a reflection of reduced contribution of domestic factors as a result of intervention, Fry-McKibbin and Wanaguru (2013) have shown that intervention absorbs only a small portion of the volatility that is attributed to the domestic factor. 
Table 3

Volatility Decomposition during the Crisis Period, in per cent

\begin{tabular}{lrrc}
\hline \hline & Common & Numaraire & Idiosyncratic \\
\hline Non-intervention days & & & \\
\hline EURO & 44.499 & 19.792 & 35.709 \\
GBP & 42.101 & 3.179 & 54.720 \\
INR & 11.281 & 3.144 & 85.575 \\
JPY & 3.213 & 3.522 & 93.266 \\
PKR & 0.063 & 2.556 & 97.381 \\
USD & 3.010 & 19.962 & 77.038 \\
\hline Intervention days & & & \\
\hline EURO & 38.789 & 13.312 & 47.898 \\
GBP & 66.386 & 11.808 & 21.806 \\
INR & 8.650 & 12.937 & 78.413 \\
JPY & 10.265 & 13.122 & 76.613 \\
PKR & 0.524 & 15.372 & 84.105 \\
USD & 0.038 & 13.931 & 86.030 \\
\hline \hline
\end{tabular}

Note: Volatility decomposition is based on the contribution to the total volatility. Exchange rates are expressed against 1 unit of the Sri Lankan rupee.

Notably, the factors uniquely associated with all currency markets except for the euro market tend to affect the respective currencies by explaining more than 50 percent of their volatilities in non-intervention days. Except for the case of the Indian rupee, the magnitude of this influence is larger compared to the results reported for the pre-crisis period. These results provide evidence of the increased volatility in foreign exchange markets around the world after 2007. Although, the volatility in the Indian foreign exchange market related factors is smaller than the non-intervention day results reported for the pre-crisis period, it still exceeds 85 per cent of total volatility of the Indian rupee/Sri Lankan rupee exchange rate returns.

During the intervention days, the contribution of the idiosyncratic US and Euro foreign exchange market related factors have increased, suggesting that the Central Bank has responded to the volatility increase in these foreign exchange markets in the face of the recent US and euro based crises. The volatility decomposition also reveals that the contribution of the numaraire factors of the US dollar/Sri Lankan rupee and the euro/Sri Lankan rupee returns have decreased compared to the non-intervention day volatility. Together, these results suggest that the Central Bank of Sri Lanka tries to shield its domestic foreign exchange market against possible adverse effects coming from crisis originated 
countries. Though it is debatable whether a country, especially a small open economy like Sri Lanka, can curb externally sourced volatility effects by adjusting domestic policies, the Sri Lankan Central Bank's action can be interpreted as a way of preventing the spread of the effects of the crisis in to the foreign exchange market in Sri Lanka.

As a diagnostic test, the significance of the structural break terms introduced to the model for the crisis period were tested using the Wald test and all the structural break parameters were found to be jointly significant with F-test of 2084.23 (with $p$-value of 0.000 ).

\subsection{The period after changing the policy stance}

The exchange rate policy in Sri Lanka has not changed much since the introduction of the floating exchange rate regime in January 2002. Although the Central Bank of Sri Lanka followed the floating exchange rate since 2002, it reserved the right to intervene in the foreign exchange market either to build up the country's stock of international reserves or to curb excess volatility in the market as is the convention in any central bank who follow the floating exchange rate policy. History shows that the central bank has intervened in the foreign exchange market frequently until 2012. However, the Central Bank decided,

Table 4

Volatility Decomposition in the Period after February 2012, in per cent

\begin{tabular}{crcc}
\hline \hline & Common & Numaraire & Idiosyncratic \\
\hline Non-intervention days & & & \\
\hline EURO & 7.200 & 25.088 & 67.712 \\
GBP & 14.264 & 34.726 & 51.009 \\
INR & 43.877 & 23.964 & 32.159 \\
JPY & 13.146 & 45.483 & 41.371 \\
PKR & 5.480 & 62.004 & 32.517 \\
USD & 5.617 & 55.544 & 38.839 \\
\hline Intervention days & & & \\
\hline EURO & 27.188 & 6.762 & 66.050 \\
GBP & 17.711 & 6.681 & 75.608 \\
INR & 37.781 & 8.745 & 53.475 \\
JPY & 33.246 & 7.847 & 58.907 \\
PKR & 81.495 & 7.271 & 11.234 \\
USD & 60.702 & 6.142 & 33.156 \\
\hline \hline
\end{tabular}

Note: Volatility decomposition is based on the contribution to the total volatility. Exchange rates are expressed against 1 unit of the Sri Lankan rupee. 
on February 09, 2012, to limit its intervention in the domestic foreign exchange market to allow more flexibility in determining the exchange rate.

This section re-runs the factor model of exchange rate returns for the period from February 09 to August 30, 2012 to identify the contribution of each factor to the total volatility of exchange rate returns of the six bilateral exchange rates after limiting intervention by the Central Bank. Results are reported in Table 4. The estimated model satisfies the $J$ - test with $p$-value of 0.948 .

The volatility decomposition reported in Table 4 is strikingly different from the crisis period results reported in Table 3. The euro/Sri Lankan rupee and the British pound/Sri Lankan rupee exchange rate volatility on non-intervention days now stems from factors uniquely attributed to the European and the UK currency markets, reflecting the higher exchange rate volatility in the currency markets in the Euro area that spills-over to the other currency markets. The percentage contributions of the idiosyncratic factor of all other currency markets on non-intervention days are lower than the contribution of the crisis period. Notably, most of the volatility of the Indian rupee/Sri Lankan rupee exchange rate comes from factors common to all currency markets.

The percentage contributions of the numeraire factor to the total volatility of all the exchange rate pairs in the model on non-intervention days play an important role after the change in exchange rate policy in Sri Lanka. This suggests that the volatility of the foreign exchange market during this period is mainly driven by shocks which stem domestically. Specially, the numaraire factor accounts for 56 per cent and 62 per cent in US dollar/Sri Lankan rupee and Pakistan rupee/Sri Lankan rupee exchange rate volatility, respectively.

Decomposition of exchange rate volatility on intervention days is clearly different to the decomposition results reported in both the pre-crisis and crisis periods. Most interestingly, it is observed that the contribution of the factors unique to the domestic foreign exchange market (numaraire factor) decreases as the Central Bank intervenes in the currency market. Further, the factors common to all currency pairs in the model (common factor) now play a major role in the volatility decomposition of the US dollar/Sri Lankan rupee and Pakistan rupee/Sri Lankan rupee exchange rate volatilities. For all other currency pairs, factors unique to the respective currency markets make the highest contribution to the exchange rate volatility. Most importantly, the sizable contribution of the factors uniquely associated with the European and the UK currency markets (idiosyncratic euro and GBP factors) are higher, reflecting the higher currency and financial market volatility which prevails in the European region. 
The volatility decomposition on intervention days highlights some important insights. First, the results clearly show that the Central Bank of Sri Lanka has changed its exchange rate policy stance. Specially, intervention does not aim volatility uniquely associated with the US currency market. Further, these results suggest that the new policy stance which is following by the Central Bank has been able to curtail the shocks which originate domestically. More than 90 per cent of the currency market volatility on intervention days is now attributed to the shocks coming from external factors. This implies that the recently adopted exchange rate policy stance is appropriate in curtailing the effects of domestic factors. These results, in turn, suggest that the Central Bank has to change its policy stance towards the foreign exchange market from time to time, in line with developments in the foreign exchange markets. However, further research is needed to assess robustness of these findings as the empirical analysis is limited to a relatively short period.

\section{Concluding Remarks}

Decomposition of exchange rate volatility to identify the magnitude of the contribution of external factors and factors unique to the domestic currency market to overall volatility of the exchange rate return is a cluttered area of international finance. This paper attempted to fill that gap in the literature using high frequency data on six currencies namely euro, the British pound, the Indian rupee, the Japanese yen, the Pakistan rupee and the US dollar, all expressed against the Sri Lankan rupee. The period considered was extended from January 2002 to August 2012. This period was divided into two periods: the pre-crisis period which covered the period from January 2002 to June 2007, and the crisis period which covered the period from July 2007 to August 2012. An additional empirical investigation is carried out for the period from February 2012 to August 2012, to capture the impact of the structural change after limiting foreign exchange intervention by the Central Bank of Sri Lanka. A latent factor model, which is considered as a parsimonious way of modelling common shocks that underlie the co-movements of large time series was applied as the empirical methodology. The model was accomplished through GMM, distinguishing days on which the Central Bank intervenes and does not intervene in the foreign exchange market.

The factor structure allowed disentangling unconditional exchange rate volatility into three factors; two factors attributed to external shocks and one factor attributed to the domestic currency market. This paper offers empirical evidence that the volatility of exchange rate returns in Sri Lanka is mainly driven by externally sourced shocks. The empirical results for both the pre-crisis and crisis periods suggest that the Central Bank of Sri Lanka mainly responds to externally sourced factors rather than factors uniquely associated with the domestic foreign exchange market. Specifically, the Central Bank's 
focus is the volatility that comes from major currency markets. The Central Bank's policy response was mainly aimed at the idiosyncratic US currency market related factors during the pre-crisis period, and to the idiosyncratic euro and US currency market factors during the period related to the recent financial crisis. The latter suggests that the Central Bank has attempted to shield its currency market against the shocks coming from the two crisis originating countries' currency markets. However, it would be more interesting if it identifies whether this higher contribution of the idiosyncratic euro and US factors is merely a spill-over effect or mainly driven by contagion effect, which appears only in crisis periods. This is left for future research. Both the pre-crisis analysis and the crisis period analysis reveal that the Central Bank can play only a limited role as the volatility of the exchange rate is mainly attributed to external factors. Despite the fact that the crisis in the Euro area is still evolving, the current exchange rate policy stance introduced at the beginning of 2012 has had the effect of reducing volatility that stems from domestic currency market related sources.

This paper highlights some important policy implications for central banking practice in Sri Lanka and, potentially, other small open economies. The Central Bank of Sri Lanka has limited scope in mitigating exchange rate volatility when such volatility comes from external sources. Specifically, frequent intervention in the foreign exchange market does not seem to absorb volatility unique to the domestic currency market in such circumstances. Instead, intervening in the foreign exchange market when its volatility is mainly driven by domestic factors (isolated intervention) is shown to be more effective.

This study stands as an early attempt in applying the latent factor model to decompose exchange rate volatility in Sri Lanka. Therefore, it emphasizes the need for further research in this line of study. Although the latent factor model overcomes the issues related to conditioning on observed data to identify the sources of exchange rate volatility, which, in turn stands as a limitation of this methodology as it does not identify the role of any particular observed variable. Though challenging, research to overcome this limitation would be a significant contribution in the field of international finance. 


\section{References}

Abdalla, S. Z. S. (2012). Modeling Exchange Rate Volatility using GARCH Models: Empirical Evidence from Arab Countries. International Journal of Economics and Finance 4(3), 216-227.

Bai, J. and S. Ng (2006). Evaluating Latent and Observed Factors in Macroeconomics and Finance. Journal of Econometrics 131(1), 507-537.

Berument, H. and M. Pasaogullari (2003). Effects of the Real Exchange Rate on Output and Inflation: Evidence from Turkey. The Developing Economies 41(4), 401-435.

Canales-Kriljenko, J. and K. Habermeier (2004). Structural Factors Affecting Exchange Rate Volatility: A Cross-section Study. IMF Working Paper (04/147), 1-13.

Cragg, J. G. (1983). More Efficient Estimation in the Presence of Heteroscedasticity of Unknown Form. Econometrica 51(3), 751-763.

Diebold, F. and M. Nerlove (1989). The Dynamics of Exchange Rate Volatility: A Multivariate Latent Factor ARCH Model. Journal of Applied Econometrics 4(1), $1-21$.

Dungey, M. (1999). Decomposing Exchange Rate Volatility Around the Pacific Rim. Journal of Asian Economics 10(4), 525-535.

Dungey, M., R. Fry, B. Gonzalez-Hermosillo, and V. Martin (2005). Empirical Modelling of Contagion: A Review of Methodologies. Quantitative Finance 5(1), 9-24.

Dungey, M. and V. Martin (2004). A Multifactor Model of Exchange Rates with Unanticipated Shocks: Measuring Contagion in the East Asian Currency Crisis. Journal of Emerging Market Finance 3(3), 305.

Engel, C., N. C. Mark, and K. D. West (2012). Factor Model Forecasts of Exchange Rates. National Bureau of Economic Research, Working Paper No. 18382.

Engle, R. F., T. Ito, and W. Lin (1990). Meteor Showers or Heat Waves? Heteroskedastic Intra-daily Volatility in the Foreign Exchange Market. Econometrica 58(3), 525-42.

Fry-McKibbin, R. and S. Wanaguru (2013). Currency Intervention: A Case Study of an Emerging Market. Journal of International Money and Finance 37, 25-47.

Hamilton, J. (1994). Time Series Analysis, Volume 2. Cambridge University Press. 
Heston, S. L. and K. G. Rouwenhorst (1995). Industry and Country Effects in International Stock Returns. The Journal of Portfolio Management 21(3), 53-58.

Ito, T. and K. Sato (2008). Exchange Rate Changes and Inflation in Post-Crisis Asian Economies: Vector Autoregression Analysis of the Exchange Rate Pass-Through. Journal of Money, Credit and Banking 40(7), 1407-1438.

Karras, G., J. M. Lee, and H. Stokes (2005). Sources of Exchange-rate Volatility: Impulses or Propagation? International Review of Economics and Finance 14(2), 213-226.

Kose, M. A., C. Otrok, and C. H. Whiteman (2003). International Business Cycles: World, Region and Country-Specific Factors. American Economic Review 93(4), 1216-1239.

Mahieu, R. and P. Schotman (1994). Neglected Common Factors in Exchange Rate Volatility. Journal of Empirical Finance 1(3-4), 279-311.

Newey, W. and K. West (1987). A Simple, Positive Semi-definite, Heteroskedasticity and Autocorrelation Consistent Covariance Matrix. Econometrica: Journal of the Econometric Society 703-708.

Ng, V., R. F. Engle, and M. Rothschild (1992). A Multi-dynamic Factor Model for Stock Returns. Journal of the Econometrics 52(1), 245-266.

Odusola, A. F. and A. E. Akinlo (2001). Output, Inflation and Exchange Rate in Developing Countries: An Application to Nigeria. The Developing Economies 39(2), 199-222.

Stančík, J. (2009). Determinants of Exchange Rate Volatility: The Case of the New EU Members. Czech Journal of Economics and Finance 57(9-10), 414-432.

Verdelhan, A. (2012). The Share of Systematic Variation in Bilateral Exchange Rates. Unpublished manuscript.

Wooldridge, J. M. (2001). Applications of Generalized Method of Moments Estimation. The Journal of Economic Perspectives 15(4), 87-100. 